\title{
CULTURAL VARIATION AND PARENTING STYLE
}

\section{Dr. Kanchan Jamir}

\section{Asst. Prof. Dept. Of Psychology, Pt,jawaharlal Nehru Govt.college, Faridabad} Haryana

\section{ABSTRACT The present study is an attempt to find out the impact of cultural variation on parenting style. In this study} eighty students from different religious background were taken. Cross cultural variation and grades were taken as independent variable and school related outcome and style of parenting were employed as dependent variables.

\section{KEYWORDS : Cultural Variation, Parenting Style}

Every culture has it's own values, traditional, rituals, sanctions and norms. There has been increasing realization that imperative change due to dynamism of environment can be facilitated by understanding and recognition of cultural dimensions of the society. Cultural norms and values are deeply rooted and no fundamental change can be brought and stabilized by ignoring culture. Procedure and mechanism for introducing accepting and assimilating changes are present in every culture. It will be inappropriate to perceive all current Indian values as wrong and making effort to change them. Rather these are certain values, which need to be preserved and nurtured. They can give us a cultural edge. Such Differentiation requires vision, analysis of the cultural dimensions Saraswathi, T.S. (Ed.) (1999)

Culture has been defines differently by many intellectuals. Mazumdar and Madan Present culture as the life style of the person. According to Tylor. "Culture is that complex whole which includes knowledge, belief, art, morals law, custom and any of other capabilities and habits acquired by man as a member of society. It is apparent that culture is the social heritage a gift to human being given by society. It is the total way of life and psychophysical and means upon which the particular life style is based.

This particular notion is also presented by Bidney (1953). He states that culture is the product of agrofacts, mentifacts, antifacts and sociofacts. In his own words - "In culture come the behaviour, made or acquired by men, within society along with social, utestic and social uerfues and organizations which are accepted by the social members and their (social members) endeavours of act." In accordance with pdingten 1952- "Culture is the gross total of that materialistic and intellectual means and material following which a person adapts the environmental demands and gratifies his/her biological and social demands".

Piddengton has clarified culture in two ways. They are as follows:

(i) Materialistic Culture: Man made things of civilization like television, computer, home etc.

(ii) Im Material Culture: Knowledge, belief, values, systems, laws, institution etc both aspects of culture are coincidental.

Herskovits (1957) believes culture as the man made part of environment. He follows Piddeisgton and states two aspects of culture e.g. natural or God gifted and materialistic or manmade culture. Linton defines culture as the sun total of knowledge, attitudes and natural behaviour patterns showed and transmitted by the members of a particular society.

Thus it is apparent that it is very difficult job to provide an universally accepted definitions of culture. "Culture in total can be defines as a particular life style, adjustment pattern and behavioural norms of a particular society. Culture is comprised with all sorts of ideas and behaviour which are acquired by a person through structural interaction. A person gets them by vocals, postures and examples not by the heredity" Gupta \& Sha (2001)

\section{NATURE OF CULTURE:}

There are many characteristics of culture and they are as follows:

(i) Culture is Man Made: Culture can only be seen in human society. There are some psycho physical characteristics in human which discriminate him from other species. Because of his developed intellect he discovers many news dimensions of account. Due to cultural enrichment a person is considered as super organic.

(ii) Culture is Learned: Culture is the sum total of behaviour standards that are learned by the human being by the society prevailing around him. This process is called socialization. Although a person learns so many things for his personal use as well as of welfare but it can not be considered as culture. Behaviours that are meant for many groups majorities or society, culture is formed by them. Group behaviour genera to customs traditions or stereotypes and they can only be seen in human society.

(iii) Culture is Transmitted: Since culture can be learned hence, it is transmitted from older to younger generation. The young generations takes knowledge from the elder group and adds his own experiences and language plays a major role in this context.

(iv) Every Society has its Own Culture: A society is found different from the other because of its geographical and social circumstances. Society inverts many new ideas for the fulfillment of its demands and these inventions give a new culture to the society. Needs of a society are entirely different from the other and they cause cultural variation. But it is not the end. In spite of these culture variations there is a general similarity that can be seen in all societies. Thus it is opined that culture is accompanied by the similarities as well as differentials of the societies.

(v) Culture has Social Quality: Culture is entirely the contribution of society and its conceptions are developed in causal by society. It is emerged by group habits, behaviors and experiences. The Components of culture eg. Customs, language art tradition, religion, science, philosophy presents not only the life style of a person but also represents the life strategy of the whole society.

(vi) Culture is ideal for the group: The People of a given culture follow the specific culture and shape themselves accordingly. When two cultures are compared it is very difficult for the psychology to make the distinction.

(vii)Culture satisfies Human Needs: It is the primitive quality of a living in that particular culture: There are many psychophysical and social needs of a person and he has 
formed culture in order to meet his demands of life.

(viii)Culture has Adaptability: Culture has a quality on the basis of which a person adjusts himself according to time society and other circumstances.

(ix) Culture has the Integrative Quality: Culture is comprised of many units. Social units like culture trait and culture complex are embedded. Interpretation of units forms a culture and maintains its systems.

(x) Culture is Fundamental in Forming Human Personality: The relative significance of culture environment and soaks its properties into himself. The major effectors of culture are rituals, customs, religion, philosophy, art, science and behavior and they lay their print on the person.

(xi) Culture is Both super Individual and Super Organic: The meaning of super individuals denotes that culture is not formed by any particular and it consumes not only one part of the culture but culture is formed by total segment. On the ground of this discussion it can be said that culture has its own consistency and it is comprised with so many features.

Thus, it is surely fair to say that human behavior is a gross product of consequences of person $\mathrm{x}$ environment interaction. Also, it is governed by the internal difference that a person may have. Thus, it can be said that it impacts and structures the behavioral pattern in a particular spectrum. In this study an attempt was made to delineate the patterns of human behavior (as revealed by Hindu, Muslim, Sikh and Christians).

\section{PARENTING}

'Parenting' is intrinsically a matter of cultural construction and very much a part and parcel of the complex social orders which a group of people in habit.

It engages a relatively prolonged phase of adult human life. The Oxford English Dictionary (1996) defines parenting as 'the single-minded' unconditional desire to provide a loving, caring home' [p.1521]. As an art of creating an environment for children parenting allows them to grow into wholesome and healthy adults. Thus parents have an enormous responsibility to provide for all the basic needs of children who during early years are totally dependent on them. In essence parenting is the recognition by each individual of his or her responsibility to product, care for and nurture the young.

Deliberating upon care giving (parenting) Bornstein (1995) has delineated its four essential functions: (a) nurturing care giving meets the physical requirements of the child. (b) Material care giving constructs and organizes the child's physical world, (c) social care giving includes the variety of behaviors parents use engaging their children in interpersonal exchanges, and (d) didactic care giving consists of the variety of strategies parents use in stimulating children to engage in and understand the world outside the parent child dyad. This view offers a broad perspective on parenting. First, it does not limit parenting to biological parents: other biological relations and caretakers who are unrelated to the child may also be centrally engaged in it. The assumption that mothers as primary caregivers have the most powerful effects on their children's development is open to question. Second, Bornstein makes the point that parenting is a relationship that unfolds over a period of time. Third, he emphasizes the responsibilities of parents to socialize children to help them become well-functioning members of the culture in which they are born and grow. Fourth, parenting is not limited to what parents believe about child rearing or how they behave towards their children but considers the question of how parents create family environments that foster children's development. Thus, the process of parenting in not confirmed to the relationships between an adult and his/her biological offspring, but occurs whenever an individual takes an active role in the process of helping a child to grow and develop.

Parenting can be viewed as transaction a task involving two parties-the parents and the child. It is not a quality or characteristic of individuals. It can be best seen as an ongoing process in which a torch, as it were passed from generation to generation, grows brighter of dimmer. As an old Jewish proverb says "more than the calf wishes to suck, the cow wishes to give suckle". This underscores the fact that the parent-child relationship involves reciprocity; the parent provides love and material support while the child responds with affection and obedience. At the level of collectivity parenting constitutes key process in any civilization. It is an intentional or deliberate process ensuring familial and societal continuity. In general, parents wish to ensure the well being of societal offspring's. They want their children to be successful in the different walks of life, to take pride in their heritage, to be respectful towards elders and to live happy and healthy lives both physically and mentally.

While analyzing parenting Ruddick and Neill (1979) draw attention to two analogies of parents: Parents as gardeners and parents as guardians. Parenting is often compared to various adult occupations like sculpting, teaching, governing, animal training, and financial investing. But the oldest and perhaps most relevant analogy is, to gardening. According to this analogy parents are relegated to the role of conscientious gardeners who plant the seed where it will received adequate nutrients from the soil, provide optimal amounts of water and sunlight, and wait for the internal processes to unfold and reveal what kind of flower has emerged. The gardening analogy reflects the fact that a child is parents' product, the result of intentional effort, none the less a product with the unique capacity to become the equal of its producers. Hence, child producers may not treat children as if they were and would remain mere artifacts or property. The analogy that defines parents as guardians focuses on the concern about the child's well being. Parents are seen as procreators who are entrusted by God with the general well being of the "necessities of life" including the capacity for producing and guarding a life of its own.

In psychological literature the relationship parents-child has traditionally been dealt with in the context of attachment between mother and child. It has been reported to have lifelong effects on relationship with loves ones as it provides the child with emotional security (Anisworth et. Al., 1978; Harlow, 1969). The closeness to mother is necessary for healthy and secure attachment. Human infant enter the world with what seems to be distinct disadvantage when compared with the majority of animals. They are helpless and are totally dependent on others for survival. Since they have no complex instinctive programming is far more difficult and variegated than that of other animals. This is achieved through the complex process of socialization parenting.

\section{REFERENCES}

1. Ain's worth, M.D.S.,Bleher, M.C.; Walters, E and Wall, S (1978). Patterns Of attachment, Hillsdale N.J.Erbaum.

2. Harlow, H.F. (1969) Age mate of peer affectional system D.S. Lehrenan. R.A.Hinde, and E shaw (Eds) Adances in the study of behavior (Vol 2 pp. 333383) New York academic.

3. Ruddick, W. and Neill, O. (1979). Having children, Philosophical and legal reflection on parenthood, New York Oxford University Press.

4. Bornstein, M.H.(1995). Parenting infant, M.H.Bornstin (ed) Handbook of Parenting. Hillsdale, N.J.Erlbaum.

5. Saraswathi, T.S. (Ed.) (1999). Culture socialization and human development Theory research and applications. India New Delhi Sage. 